\title{
Non-Contact Internet Sex Crimes against Minors: A Review through Comparative Law
}

\author{
By Limor Ezioni*
}

Legal systems in the Western World have enacted extensive laws regarding sex crimes against minors, the advent of the internet has raised new problems, in terms of the actual protection the law provides from attacks through this medium, as well as the type of protection the law should be able to provide. To what degree can the law convict a person of a sex crime when no physical contact was made with the victim? Is the trauma experienced by a victim of an internet-facilitated sex crime qualitatively different than the trauma experienced by the victim of a direct sex crime? To what extent is the law capable of effectively policing the use of a medium so ubiquitous as to be, for all intents and purposes, inescapable? This article reviews the implementation of these legal strategies in various countries, examine the socio-legal aspects of their specific instantiation, as well as address the relatively new social phenomenon of teen sexting and discuss the different aspects of sex crimes committed online as opposed to those committed in person and why legislation and law enforcement should adapt accordingly to the rapid changes these new types of sex crimes present.

Keywords: Sex Crime; Minors; Internet; Law.

\section{Introduction}

All countries in the Western World view sex crimes, especially those against minors, as among the worst criminal offences one can commit. Rightfully so as sex is an intensely personal act which demands the autonomy of its participants. Disregard of the need for autonomy in a sexual context can result in physical and emotional trauma, and these effects are exacerbated in minors, the healthy development of whose sexual identities may likely be disrupted by the crime.

While the legal systems in the Western World have enacted extensive laws regarding sex crimes against minors, the advent of the internet has raised new problems, in terms of the actual protection the law provides from attacks through this medium, as well as the type of protection the law should be able to provide. To what degree can the law convict a person of a sex crime when no physical contact was made with the victim? Is the trauma experienced by a victim of an internet-facilitated sex crime qualitatively different than the trauma experienced by the victim of a direct sex crime? To what extent is the law capable of effectively policing the use of a medium so ubiquitous as to be, for all intents and purposes, inescapable?

All these questions and more demand consideration by all parties involved in the shaping of the law. There are two common avenues that Western legal systems legislators have enacted specific sex crimes in which the internet was the medium of

${ }^{*}$ LL.D.; Dean, The Academic Center of Law and Science, Hod-Hasharon, Israel. I would like to thank my research assistant, Ms. Shany Schvartz, for her dedicated work and contribution to this article.Email: le@limorezioni.com. 
connection between the perpetrator and the victim. This avenue gives voice to the public's view of these crimes and makes it ever simpler for the judiciary to prosecute.

The second avenue that has been employed in the legal fight against internetfacilitated sex crimes against minors is police cyber units. Many countries have established independent cyber units wholly dedicated to tracking known or suspected perpetrators of such crimes, preventing and pre-empting such attacks and protecting minors who are at risk of falling victim to them.

Herein I will review the implementation of these legal strategies in various countries, examine the socio-legal aspects of their specific instantiation, as well as address the relatively new social phenomenon of teen sexting and discuss the different aspects of sex crimes committed online as opposed to those committed in person and why legislation and law enforcement should adapt accordingly to the rapid changes these new types of sex crimes present.

\section{The Unique Nature of Internet Sex Crimes against minors}

\section{How Social Online behaviour affects Minors' Judgment}

To have a better understanding as to why minors are being easily targeted as potential victims for online sex crimes, it is important to examine the somewhat recent phenomenon of "Sexting"' and how it affects the impressionable mind of minors as they encounter online predators disguising themselves as fellow minors.

Sexting has begun to receive legislative attention only within the last few years. The nature of the crime is determined by the age of the subject matter, without regard to the age of the sender, thus making it a crime to send or receive any material depicting minors in any sort of sexual context. Sexting is also a crime when the minor sends photos of themselves ${ }^{3}$.

However, as research shows, Sexting has become somewhat common and frequent social media behaviour for minors in recent years. This type of online behaviour can fog the developing judgment of said minors, who assume it is "ok" to send self-photographs (also referred to as "selfies") to one another or to one's romantic interests, thus making the minor more susceptible to agree to take and send photos or videos of themselves or show themselves online via webcam when they assume the person they are conversing with online is a peer.

This avenue is used by child predators who pretend to be a peer-minor online to lure minors into producing such pornographic material of themselves. This material is then used to blackmail the minor into committing furthermore lude and damaging acts on themselves.

\section{The Nature of Internet Based Sex Crimes}

Special laws are needed for internet-based sex crimes simply because of the unique nature of these crimes. There is lack of a physical actus reus on the part of the predator who uses the internet to connect with his prey and without any physical contact with

\footnotetext{
${ }^{2}$ A term derived from the joining of "sex" and "texting". Sexting includes the sending or receiving of sexual explicit photographs of one's self or written messages of explicit sexual nature.

${ }^{3}$ For additional information on relevant legislation in the various states please see: Craig Bartholomew Legare v. Her Majesty the Queen (Can.), Adam Walsh Act (US), and Criminal Code Act 1995 (Australia)
} 
the victim - uses communication and intimidation to have them preform the sexually explicit acts on themselves. This lack of physical contact is not only a component that predators try to use as a defence but can potentially present a challenge to determining that all the necessary elements of the crime have been fulfilled. After all, the predator's sole action towards the victim is communication. It is the victim who carries out the physical elements of the crime on themselves. Can we punish a predator for an act committed by a victim? This challenge is the reason why the Canadian criminal code criminalises the simple facilitation of a potential sexual situation; ${ }^{4}$ why America enacted a set of legislation solely regarding the use of the internet in sexually preying on minors; ${ }^{5}$ why Australia's criminal code has an entire section that deals with employing computers in committing sex crimes. ${ }^{6}$ Without laws tailored to this specific situation in place, it can be difficult for a judge to legally justify sentencing a predator to the degree that he would wish to do so. The mens rea of the predator may be complete, but without a physical action to explicitly give voice to the mens rea, and without specific legislation for such precarious actus reus, a judge is confined only to what the law prescribes.

\section{Foreign Legislation}

\section{Overview of Relevant Laws}

Many countries have amended sections to their criminal code to deal with internet sex crimes in general, and those against minors specifically, or have enacted acts which exclusively deal with such crimes. The United States, for example, has both types of legislation. Chapter 110 of Title 18 of the Federal Code is dedicated to sex crimes against children. Additionally, the Adam Walsh Child Protection and Safety Act of 2006 is an independent act purposed to protect children from the various dangers posed by potential perpetrators of sex crimes via the internet.

Chapter 110 of Title 18 of the Federal Code deals with a long list of crimes, and numbers 21 sections. ${ }^{7}$ Because the United States Congress is limited to the legislation of laws which are subsumed fewer than one of the enumerated powers, of which sex crimes are not included, the authority to enact these crimes is that of the Commerce Clause. ${ }^{8}$ This connection is made explicit in several sections, in which a necessary circumstance for the establishment of the crime is that the act or item has bearing on interstate commerce. ${ }^{9}$ The sections of the chapter are composed painstakingly minutely, enumerating a seemingly exhaustive list of the various alternatives that may constitute forms of transport. Among these alternatives are listed computers and electronic transmissions. ${ }^{10}$ In Section 2256, "Definitions for Chapter," a "visual depiction" "includes undeveloped film and videotape, data stored on computer disk or by electronic means which is capable of conversion into

\footnotetext{
${ }^{4}$ Craig Bartholomew Legare v. Her Majesty the Queen (Can.).

${ }^{5}$ Adam Walsh Child Protection and Safety Act (US).

${ }^{6}$ Criminal Code Act 1995 (Australia).

${ }^{7} 18$ U.S.C. $\$ \$ 2251-2260$ A (2006)

${ }^{8}$ By way of the Necessary and Proper Clause, U.S. CONST. art. I, §8.

${ }^{9}$ See, for example, 18 U.S.C $§ 2251$, "Sexual Exploitation of Children": "Any person who employs, uses, persuades, induces, entices or coerces... or who transports any minor in or affecting interstate or foreign commerce... with the intent that such minor engage in any sexually explicit conduct..."

${ }^{10} 18$ U.S.C. $\$ 2251(\mathrm{~d})(2)$.
} 
a visual image." 11 In that same section, "Child Pornography" is defined as "any visual depiction, including any photograph, film, video, picture, or computer or computergenerated image or picture $[\ldots]$ of sexually explicit conduct $[\ldots]]^{\prime 12}$

In addition to provisions within the Federal Code, Congress enacted the Adam Walsh Child Protection and Safety Act in 2006, whose stated mission is "To protect children from sexual exploitation and violent crime, to prevent child abuse and child pornography, to promote internet safety, and to honour the memory of Adam Walsh and other child crime victims." ${ }^{" 13}$ Among the provisions of the Act, Title II gives enhanced authority to the federal law in protecting children against the threat of such crimes ${ }^{14}$. Its sections significantly rise the minimum prison terms for various crimes from their initial terms as set out in Title 18 of the Federal Code. ${ }^{15}$

The express listing of computers as a channel through which one may commit a crime of sexual exploitation against minors has been employed, challenged, reviewed and upheld in federal court. In Demink ${ }^{16}$, the petitioner, Steven Demink, appealed for a Vacate, Set Aside or Correct Sentence ${ }^{17}$ for the life sentence he received on August 6, 2012 for multiple crimes of sexual exploitation of minors. Demink partially based his appeal on the claim that his legal counsel was ineffective on several counts, one of which being that they allowed him to plead guilty to a two point enhancement of the crime of soliciting a child for sexual conduct due to his use of a computer in the execution of said crime. ${ }^{18}$ According to Demink, because the use of a computer is listed in the section of the Criminal Code that deals with soliciting a child for sexual conduct it should not be considered an enhancement. The appeals court rejected his claim, noting that the use of the computer is not a necessary element to the crime, and therefore warrants an enhancement to the punishment.

In the United Kingdom, specific legislation was enacted in 2003 to cover the spectrum of sex crimes. ${ }^{19}$ The first part of the Sexual Offences Act 2003 lists specific crimes, and all sexual offences involving the penetration of a child under 13, or having the child penetrate another with his own genitals, committed by an adult, are punishable by life imprisonment. ${ }^{20}$ The second part of the act lists the pieces of information that various types of offenders are required to provide to police; among them are the offender's address and national insurance number. ${ }^{21}$ The act also authorises the Court to issue Sexual Harm Prevention Orders (SHPO), individual orders tailored to the situation of a specific offender who is suspected to again cause harm to "children or vulnerable adults," or to a specific child or vulnerable adult. ${ }^{22}$ Similarly, a police chief or director general is authorised to issue Sexual Risk Orders. These individual orders are tailored to a person in the authority's district who has exhibited sexual behaviour that raises suspicions that the person may pose a sexual risk to the public in general or to a specific child or vulnerable adult. ${ }^{23}$ These

\footnotetext{
${ }^{11} 18$ U.S.C. $\S 2256(5)$.

${ }^{12} 18$ U.S.C. $\$ 2251(8)$.

${ }^{13}$ Adam Walsh Child Protection and Safety Act (US).

${ }^{14}$ Ibid. Title II: Federal Criminal Law Enhancements Needed to Protect Children from Sexual Attacks and Other Violent Crimes.

${ }^{15}$ Ibid. $\$ \$ 202-208$.

${ }^{16}$ Demink $v$. United States of America

${ }^{17} 28$ U.S.C. $\S 2255$ (1949).

${ }^{18} 18$ U.S.C. $\S 2251$.

${ }^{19}$ Sexual Offences Act (2003).

${ }^{20}$ Ibid, part 1.

${ }^{21}$ Ibid, part 2 .

${ }^{22}$ Ibid.

${ }^{23}$ Ibid.
} 
orders can be put in place for a maximum of two years, and SHPOs can be in place for a maximum of five years. Both orders may include limitation on travel outside the United Kingdom and may require the subject to surrender his passport for the duration of the order.

The relevant laws in Germany are listed in Chapter 13 of the Criminal Code, entitled "Offences against Sexual Self-Determination." ${ }^{24}$ Among the offences against minors, the Code has a graduated system of punishment based on the age of the victim: any victim under 18 is considered a minor, while there is a higher punishment for victims less than 16 years of age, and that punishment doubles for victims less than 14 years of age (a "Child"). ${ }^{25}$ Section 176a includes a comprehensive list of factors that aggravate the preceding offences. ${ }^{26}$ Of particular interest on this list is that penetration of the child, or having the child penetrate another, are considered aggravating factors. In Section 176, which deals with the engagement of a child in sexual activity, penetration need not occur in order to complete the crime. Penetration is a more severe form of the crime, and the lack thereof does not constitute a defence for the accused.

Section 184 covers pornography offences. ${ }^{27}$ It establishes the same punishment, a fine or a prison term of up to one year, for one who distributes pornography to a minor and for one who makes pornography accessible at a place in which a minor may see it. Section 184a gives the punishment for involvement with pornography that features violent sexual acts or bestiality. ${ }^{28}$ Section $184 \mathrm{~b}$ increases that punishment from a maximum of three years imprisonment or a fine to a maximum of five years when the pornography in question features a child, and further doubles that increased term when the offence is committed on a commercial basis. ${ }^{29}$ If the pornography features a juvenile, a minor between 14 and 18 years of age, $184 \mathrm{c}$ removes the possibility of a fine and requires the prison term set out in $184 \mathrm{a}^{30}$

The Canadian Criminal Code likewise details sexual offences in great elaboration, in Chapter 46, Section V-Sexual Offences, Public Morals and Disorderly Conduct. ${ }^{31}$ Beyond the offences themselves, Section 172.1, Offences Tending to Corrupt Morals, lists "Luring a Child" as an offence in and of itself. ${ }^{32}$ This means communicating with a minor "via telecommunication [...] for the purpose of facilitating an offence." ${ }^{33}$ Like its German counterpart, this section of the Canadian Code differentiates punishment based on the age of the victim, by ages 18,16 and $14 .{ }^{34}$ Subsections 3 and 4 of 172.1 reflect the deep anathema to sex crimes against minors by changing the burden of evidence: when there is no evidence to the contrary, any evidence at all that the accused believed the victim to be under the relevant age is sufficient evidence to prove that he did indeed believe the victim to be below that age; likewise, claiming that the accused

\footnotetext{
${ }^{24}$ Strafgesetzbuch [STGB] [Penal Code], Nov. 13, 1998,

${ }^{25}$ Ibid, $\$ \$ 174,176,184$.

${ }^{26}$ Ibid, $\$ 176$ a. Among the aggravating factors are: A repeat offence within five years of the original; that the sexual engagement with the child involves more than one person; the offence poses serious physical or emotional damage to the child; the offence is committed for the purpose of creating pornography; the offender seriously physically abuses the child and places him in danger of death.

${ }^{27}$ Ibid, $\$ 184$.

${ }^{28}$ Ibid, §184a.

${ }^{29}$ Ibid, $\$ 184 \mathrm{~b}$.

${ }^{30}$ Ibid, $\$ 184 c$.

${ }^{31}$ Canada Criminal Code, R.S.C. 1985 (§§150-182).

${ }^{32}$ Ibid, §172.1(1).

${ }^{33}$ Ibid.

${ }^{34}$ Ibid.
} 
believed the victim to be over that age is not a defence unless there is evidence to show that the accused took steps to confirm the victim's age. ${ }^{35}$

A similar stringency regarding the age of the victim is found in Section 163.1, Child Pornography: it is the same if the person who appears in the "visual representation" is actually under the age of 18 or if s/he is depicted as being under the age of $18 .^{36}$ The section also does not discriminate the means by which the pornography was produced; it is the same if it is "a photographic, film, video or other visual representation, whether or not it was made by electronic or mechanical means." ${ }^{\prime 37}$ This easily allows for the inclusion of the computer and the internet as possible channels for the production of child pornography. And again, in consonance with its German counterpart, if the child pornography was produced with the intention of making a profit from it, the Court will view that as an aggravating factor. ${ }^{38}$

\section{Nature of the Laws}

The various legislations reviewed in the previous subsection reflect the stringency with which Western Society views sex crimes against children. The nature of the crimes, as they appear in the acts and codes above, vary in certain, nuanced ways. A basic example of this is the differing section titles given to the sections of the criminal codes that cover these crimes: In Germany, one deals with crimes against "Sexual SelfDetermination," ${ }^{39}$ acts whose illegitimacy is the arena of the crime itself, that the acts target the sexual identity of the victims. Meanwhile, in Canada, the relevant section is "Sexual Offences, Public Morals and Disorderly Conduct," ${ }^{40}$ That is to say, sexual offences are problematic because of their status as immoral acts, not necessarily simply because of the danger that may result from them. This is articulated in the case, Craig Bartholomew Legare vs. Her Majesty the Queen, where taking steps to commit a sex crime against a minor was established as criminal in and of itself, without respect to the success of the attempt. ${ }^{41}$ The accused was indicted on charges of committing the luring of a child, ${ }^{42}$ and the case notes that this is a behavioural crime, not a crime of results, as evinced by the word "Facilitating." is any action that makes it easier to commit a secondary crime against a minor, and the secondary crime need not occur in order to convict for this crime. The Judge further notes that subjective intention is required for conviction; what matters is what the accused intended for in committing the act in question. ${ }^{44}$

In Australia, the grouping of sex crimes against minors is quite unique. Not all the crimes are grouped together under a heading relating to the sexual nature of the crimes, but are rather categorised based on the means by which the crimes are committed: "Offences Relating to Use of Postal or Similar Service for Child Pornography Material or Child Abuse," 45 "Offences Relating to Use of Postal or Similar Service Involving Sexual

\footnotetext{
${ }^{35}$ Ibid, subsections (3), (4).

${ }^{36}$ Ibid, $\$ 163.1$.

${ }^{37}$ Ibid.

${ }^{38}$ Ibid, subsection (4.3).

${ }^{39}$ Strafgesetzbuch [STGB] [Penal Code], Nov. 13, 1998 "Crimes against Sexual Self-Determination".

${ }^{40}$ Canada Criminal Code, R.S.C. 1985 "Sexual Offences, Public Morals and Disorderly Conduct".

${ }^{41}$ Craig Bartholomew Legare v. Her Majesty the Queen.

${ }^{42}$ Canada, Criminal Code: R.S.C. 1985 , c. C-46, $(\$ 172.1)$.

${ }^{43}$ Ibid.

${ }^{44}$ Craig Bartholomew Legare v. Her Majesty the Queen.

${ }^{45}$ Criminal Code Act 1995 Chapter 10, Subdivision B (Austl.)
} 
Activity with Person Under 16;",46 "Offences Relating to Use of Carriage Service for Child Pornography Material or Child Abuse Material." ${ }^{, 47}$ This leads to the conclusion that there are two problems which compound the criminal nature of these acts: they are sex crimes against minors, and they abuse the postal and/or carriage services which are meant to be used for the safe transport of legal items only. The use of the postal/carriage service is not an aggravating factor of the sex crime. It isn't clear that either is an aggravating factor of the other as an independent crime. What is clear is that the question of transport and jurisdiction is a main focus of the Australian Legislator: the code expressly criminalises sex crimes against minors that are committed outside of Australian jurisdiction by an Australian citizen, or anybody that is obligated by Australian law. $^{48}$

An important function that this categorization serves is the explicit criminalisation of internet ("carriage") based crimes, allowing them to stand on their own. In Adamson $v$. The Queen, ${ }^{49}$ an offender of an internet-based sex crime against a minor appealed his sentence, claiming that the severity of such sex crimes is limited by the physical distance. The court rejected his claim, based on the "Presumption of Harm." This is a persuasive presumption ${ }^{51}$ which states that any sexual activity is harmful to children. ${ }^{52}$ The application of the presumption to cases where the sexual activity took place digitally is justified by the reasoning at the basis of carriage service crimes: "[...] the principles relating to the presumption of harm [...] apply equally to cybersex offences [...]. The legislature, in enacting the provisions prohibiting the use of a carriage service to engage in sexual activity with a child, sought to implement society's detestation of the practice of encouraging children to engage in inappropriate sexual behaviour, and to protect the child from immature decisions." ${ }^{33}$ Simply put, the engagement of an immature child in any form of sexual activity is viewed by society as problematic, and all such behaviour must be criminalised. It is understood that the internet provides a unique channel of opportunity to engage in sexual behaviour with children, which, too, was expressly criminalised.

The Australian Code, though individual in its categorization, is akin to the Federal government of America's use of the Commerce Clause in order to import sex crimes into its jurisdiction. Just as Australia views the use of a means of transportation as an egregious instantiation of sex crimes, so too does America. ${ }^{54}$ The difference, however, is that while Australian law grapples with both the physical and the digital transport of pornography and other materials used to commit sex crimes against minors, ${ }^{55}$ American law places special emphasis on such material's digital transport: in addition to the examples listed above of specific sections of the criminal code, the Adam Walsh Act places this phenomenon in sharp focus:

\footnotetext{
${ }^{46}$ Ibid, Subdivision C.

${ }^{47}$ Ibid, Chapter 11, Subdivision D.

${ }^{48}$ Ibid, Chapter 8, Division 272, Subdivisions A, B, C.

${ }^{49}$ Adamson $v$ The Queen (2015)

${ }^{50}$ Ibid, sections 13,14 , and 15 .

${ }^{51}$ A persuasive presumption assumes a given claim to be true, but the claim can be proven false. The onus is on the defendant to prove that the presumption does not apply. This, as opposed to a conclusive presumption, which is always held to be true and cannot be overturned.

${ }_{52}$ Adamson $v$ The Queen, section 22.

${ }^{53}$ Ibid, section 23.

${ }^{54}$ See: 18 U.S.C. $§ 2251(d)(2) ; 18$ U.S.C. $\$ 2256(5) ; 18$ U.S.C. $\S 2251(8)$.

${ }^{55}$ See Criminal Code Act 1995.
} 
"The interstate market in child pornography is carried on to a substantial extent through the mails and other instrumentalities of interstate and foreign commerce, such as the Internet. The advent of the Internet has greatly increased the ease of transporting, distributing, receiving, and advertising child pornography in interstate commerce. The advent of digital cameras and digital video cameras, as well as videotape cameras, has greatly increased the ease of producing child pornography. The advent of inexpensive computer equipment with the capacity to store large numbers of digital images of child pornography has greatly increased the ease of possessing child pornography. Taken together, these technological advances have had the unfortunate result of greatly increasing the interstate market in child pornography." 56

While the regular mail service is mentioned in passing, the focus of this declaration is the uniquely complicated challenge that the digital age poses to the fight against child pornography. The internet allows for the instantaneous transport of materials to any corner of the earth, with no distinction of borders; the rise of the personal digital camera has made the production of such materials a possibility to anyone who so desires to do so; the ease of procuring USB keys, memory cards and external hard drives has allowed for the simple, discrete storage of large quantities of materials. The bottom line of the declaration is that the advancements of the digital age have made all aspects of the child pornography industry easy to navigate and execute. Later on, in the same section, it is noted that the vast majority of convictions for child pornography are cases in which the material was stored on a computer. ${ }^{57}$

While the description in the Adam Walsh Act focuses specifically on pornography, computers allow for the committing of other forms of sex crimes against minors as well. The ability to communicate discreetly and anonymously is a given, and while in such cases there is physical distance between the perpetrator and the victim, that is not a mitigating factor of potential damage. In US v. Cortez-Cortez, the United States Court of Appeals for the Fifth Circuit rejected the idea that an act must be inherently sexual in its nature in order to fall under the legal category of a sex act; rather, any act committed for the purpose of sexual satisfaction is categorised as such. ${ }^{58}$ In discussing what constitutes an illegal sex act and what does not, the court explicitly states that physical contact, or even physical proximity, are not necessary elements of such a crime. "Conduct can be abusive because of the psychological harm done to a minor, without any physical contact." ${ }^{, 59}$ Case law relating to State statutes has given expression to such a perspective: "We have recognised that conduct carrying the potential for psychological harm, without any physical harm, may constitute sexual abuse of a child [...]. The statute at issue [...] can be violated without a showing of physical proximity." This underscores the nefarious nature of internet-facilitated sex crimes: the actus reus need not be sexual in nature. What sexualises and criminalises these crimes are quite simply

\footnotetext{
${ }^{56}$ Adam Walsh Act, Title V., Sec. 501 (1) (C).

${ }^{57}$ Ibid, subsection (2) (A).

${ }^{58}$ United States of America v. Victor Manuel Cortez-Cortez.

${ }^{59}$ Ibid, at 359.

${ }^{60}$ United States of America v. Francisco Armando Chan-Vincente. At issue is a law from the Virginia State Code, Section 18.2-370(A)(3): "Any person 18 years of age or over, who, with lascivious intent, knowingly and intentionally commits any of the following acts with any child under the age of 15 years is guilty of a Class 5 felony: [...] Propose that any such child feel or fondly his own sexual or genital parts or the sexual or genital parts of such person or propose that such person feel or fondly the sexual or genital parts of any such child."
} 
the subjective desires of the perpetrators. It is pure mens rea, and the means by which it can be carried out are ubiquitous and unlimited.

\section{Cyber Units}

To deal with these advanced threats that the internet constitutes against the sexual security of minors, several countries have created cyber units whose exclusive purpose is to combat such sex crimes.

In 1998, the Internet Crimes against Children (ICAC) Task Force was established in the United States. ${ }^{61}$ It is part of a larger effort, Project Safe Child, which was established by the Attorney General. ${ }^{62}$ Among the stated purposes of the ICAC Task Force are the training of State and local police in the "detection, investigation and apprehension" of offenders, ${ }^{63}$ providing assistance to authorities at all stages of investigation and prosecution, ${ }^{64}$ and raising public awareness and responsiveness to such crimes. ${ }^{65}$ As defined on its website, "The ICAC Program is a national network of 61 coordinated task forces representing over 3,000 federal, state, and local law enforcement and prosecutorial agencies. These agencies are engaged in proactive investigations, and criminal prosecutions." 66

The proper functioning of the ICAC task force is subject to a slew of stipulations, meant to ensure healthy and productive operation: The Attorney General has oversight over all task forces, ${ }^{67}$ has the power to create new task forces and dissolve existing ones, ${ }^{68}$ may institute training protocol, ${ }^{69}$ and oversee that training. ${ }^{70}$ One institution of the Attorney General is the National Internet Crimes against Children Data System, which is a database shared among all task forces and law enforcement agencies that allows for realtime updating of cases. ${ }^{71}$ Every thirty days, the database is checked for high-priority suspects. $^{72}$

The cyber unit of the United Kingdom is the Child Exploitation and Online Protection (CEOP) Command, under the auspices of the National Crime Agency. ${ }^{73}$ The CEOP has much the same goals as the ICAC. It tracks known or suspected offenders, works to protect children from falling victim to them, and prepares interventions to help children who have indeed fallen victim to sexual exploitation and abuse. ${ }^{74}$ It also tracks past offenders who have not followed their requirements under the Sexual Offences Act $2003,{ }^{75}$ allowing for the disruption of their movement when necessary. In the same vein, the CEOP shares its intelligence with international bodies regarding British sex offenders

${ }^{61} 42$ U.S.C. $\$ 17612$ (1998).

${ }^{62}$ Ibid, $\S 16942$.

${ }^{63} \mathrm{Ibid}, \S 17613$ (1).

${ }^{64}$ Ibid, (3).

${ }^{65}$ Ibid, (8).

${ }^{66}$ Internet Crimes against Children Task Force,

${ }^{67} 42$ U.S.C. $§ 17612$ (B)(3)(a).

${ }^{68} \mathrm{Ibid},(\mathrm{B})(3)(\mathrm{b})$.

${ }^{69}$ Ibid, (B)(4)(a).

${ }^{70} \mathrm{Ibid},(\mathrm{B})(4)(\mathrm{c})$.

${ }^{71}$ Ibid, § 17615.

${ }^{72}$ Ibid.

${ }^{73}$ CEOP Command,

${ }^{74} \mathrm{Cbid}$.

${ }^{75}$ Sexual Offences Act (2003) (UK) Part 2; 18 U.S.C. § 2251 and Demink v. United States of America. 
who are overseas. ${ }^{76}$ According to its website, the CEOP's activity led to the arrest of 192 suspects, to the protection of 790 children, and to the dissemination of 2,886 reports to national and international intelligence bodies in 2012-2013. ${ }^{77}$

A strong cyber-unit does not obviate the need for specific legislation, but it can be a powerful tool in preventing sexual harassment and in bringing predators to justice. A competent cyber-unit, when coupled with a hotline that is solely dedicated to this cause, and which gives power back to parents who might otherwise be helpless to save their children from abuse, may prove effective not only on the defensive stratum of apprehending criminals, but also on the offensive stratum of deterring potential predators from executing their plans. If a person understands how easy it can be to be reported and tracked down, that would indeed be very likely to sway him away from criminal activity. With this intensified effort on the part of the police, and with a judicial rhetoric that gives voice to the individual nature of these crimes, it is likely that the social awareness of the danger posed by the internet in committing sex crimes against minors will lead the legislature to finally enact these necessary laws.

\section{Statistics}

According to the U.S. National Sex Offender Public Website (NSOPW), approximately 1 in 7 minors receive unwanted sexual solicitations via the internet, ${ }^{78} 1$ in 25 minors received sexual solicitations online in which the solicitor requested offline contact, ${ }^{79}$ in $27 \%$ of incidents, solicitors asked for nude photographs of the minors, ${ }^{80} 76 \%$ of first encounters between the predator and the victim take place in online chat rooms, ${ }^{81}$ and only $5 \%$ of predators pretend to be in the same age group as the victims. ${ }^{82}$

A 2013 survey, commissioned by the United Kingdom government, ${ }^{83}$ cites the following statistics: From the years 2004/2005 to 2012/2013, the number of sexual grooming offences ${ }^{84}$ jumped from 186 to 373 , a $100 \%$ increase. $^{85}$ The report cites a 2011 study ${ }^{86}$ which found that 12 percent of UK children between the ages of 11 and 16 who were surveyed, had "reported receiving or seeing sexual messages online in the past 12 months." The report notes that 2,293 reports received by CEOP between 2011 and 2012 related to indecent photos that minors had taken of themselves and sent to solicitors; of those, about one third of the minors were under the age of $15 .{ }^{87}$

\footnotetext{
${ }^{76} \mathrm{http}: / / \mathrm{www} . c e o p \cdot p o l i c e . u k / A b o u t-U s$

${ }^{77} \mathrm{http}: / /$ www.ceop.police.uk/Media-Centre/Statistics-and-facts

${ }^{78}$ U.S. National Sex Offender Public Website.

${ }^{79}$ Ibid.

${ }^{80}$ Ibid.

${ }^{81}$ Ibid.

${ }^{82}$ Ibid

${ }^{83}$ Home Office, Cyber-crime.

${ }^{84}$ Defined in the report: "Online grooming- relates to the use of digital technologies to facilitate either online or offline sexual contact with minors [...]. In the online context, social networking sites, chat rooms and gaming sites offer the same opportunities for online groomers to befriend children. Some offenders will aim to meet the victim online in order to commit a contact sexual offence; however the internet also enables offenders to limit sexual contact in an online-only environment. In this way they fulfil their sexual motivations without the added risk of meeting a child in person." Ibid, at 4.

${ }^{85}$ Ibid, at 8 .

${ }^{86}$ Livingstone, Haddon, Gorzig \& Olafsson (2011).

${ }^{87}$ Ibid, at 18 .
} 
The official statistics website of the Canadian government ${ }^{88}$ cites that 9,084 cybercrimes were reported by police to the Uniform Crime Reporting Survey in $2012 .{ }^{89} 1,441$ of these crimes, $16 \%$, were sexual in nature. ${ }^{90}$ Specifically, $6 \%$ of the crimes were the luring of a child via computer, and $9 \%$ were child pornography crimes. ${ }^{91}$ Of the crimes for which an accused was identified, $76 \%$ were male across the board, while $94 \%$ were male in crimes of a sexual nature. ${ }^{92}$

The annual statistics report of the Israeli police in 2013 reported that only $1 \%$ of the crimes from that year were sex crimes. ${ }^{93}$ However, there was also a $5 \%$ increase in severe sex crimes ${ }^{94}$ that year from 2012..$^{95}$

\section{Discussion}

There is no doubt that the phenomenon of exploiting the internet as a tool to commit sex crimes against minors is very real; society is not ignorant of this. Legislators across the western world have sought to create legal recourse to combat these crimes. The battle is fought on two strata: Proactively, on the offensive, and reactively, on the defensive. The proactive side is that which cyber-units work towards, by attempting to prevent known dangerous persons from committing one of these crimes, and by attempting to protect vulnerable children from becoming exposed to predators. Legislation- amendments to criminal codes as well as individual acts- are reactive in that they give the courts the authority to prosecute offenders who have already committed an internet sex crime, to harsh sentences.

The internet is ubiquitous- it can be accessed by any person from any computer, tablet or smartphone in any location- and once information is put there, even if one tries to erase it, it can almost always be re-accessed if someone truly wishes to do so. The internet allows for anonymity, and worse, for the changing of identity to suit the purposes of one's goals. It brings predators into the home and lacks a concrete element that a parent can point at and warn against. The ease with which one may commit a sex crime via the internet, and the refuge it offers the predator demand that it be specifically addressed by lawmakers.

That being said, some of the qualities which make the internet so dangerous a place for minors are what allow cyber-units to catch offenders. Just as marks made by minors on the internet can be tracked by predators, so too can the virtual movements and actions of predators be tracked. The ubiquitous nature of the internet allows for constant tracking of multiple targets at the expense of far less manpower than would be required for physical tracking. Virtual evidence is never truly lost; it can always be reconstructed.

\footnotetext{
${ }^{88}$ Statistics Canada (2014).

${ }^{89}$ Ibid.

${ }^{90}$ Ibid.

${ }^{91}$ Ibid.

${ }^{92}$ Ibid

${ }^{93}$ Israel Police Force Annual Report (2013).

${ }^{94}$ This category includes rape, illegal intercourse and forceful indecent assault. Ibid, at 58 .

${ }^{95}$ Ibid.
} 


\section{Conclusion}

The gravity of the challenges created using the internet in facilitating sex crimes against minors is expressed by recent legislation. Whether that legislation be in the Penal Law itself or be an independent code of criminal nature is immaterial; what matters is that there be concrete laws in place. As such, the work done by cyber-units may be awarded through the enhanced deterrence of potential offenders and the proper sentencing of convicted ones.

\section{References}

Reports

Internet Crimes against Children Task Force. DOI= https://www.icactaskforce.org CEOP Command, (last visited Oct. 28, 2015). DOI=http://www.ceop.police.uk/AboutUs/ and http://www.ceop.police.uk/Media-Centre/Statistics-and-facts/

U.S. National Sex Offender Public Website. DOI=http://www.nsopw.gov/en/Education/ FactsStatistics?AspxAutoDetectCookieSupport=1\#technology

Home Office, Cyber-crime: A review of the evidence. Chapter 3, Cyber-enabled crimes sexual offending against children. (Oct. 2013). DOI=https://www.gov.uk/govern ment/uploads/system/uploads/attachment_data/file/246754/horr75-chap3.pdf

Livingstone, S., Haddon, L., Gorzig, A. \& K. Olafsson (2011). Risks and safety on the internet: The perspective of European Children. Full Findings. London: LSE, EU Kids Online. DOI=https://www.gov.uk/government/uploads/system/uploads/attac hment_data/file/246754/horr75-chap3.pdf, p. 6.

Statistics Canada (Sept. 25, 2014). DOI= http://www.statcan.gc.ca/daily-quotidien/140 925/dq140925b-eng.htm.

Israel Police Force Annual Report, DOI= http://www.police.gov.il/Doc/TfasimDoc/ shnaton_2013.pdf, p. 50. [In Hebrew]

\section{Cases}

Adamson v The Queen (2015) VSCA 194.

Craig Bartholomew Legare v. Her Majesty the Queen and Attorney General of Canada, Attorney General of Ontario and Beyond Borders Inc. [2009] 3 S.C.R. (Can.)

Demink v. United States of America, No. 28, 2015 U.S. App. LEXIS 93797 (Mich. Dist. Ct. 2015).

United States of America v. Victor Manuel Cortez-Cortez, 770 F.3d 355, ( $5^{\text {th }}$ Cir. 2014).

United States of America v. Francisco Armando Chan-Vincente 612 Fed Appx. 240, $\left(5^{\text {th }}\right.$ Cir. 2015). At issue is a law from the Virginia State Code, Section 18.2-370(A)(3).

\section{Legislation}

18 U.S.C. $\S \S 2251-2260$ A (2006).

28 U.S.C. $\$ 2255$ (1949).

42 U.S.C. $\S 17612, \S 17613, \S 17615, \S 16942$ (1998).

Adam Walsh Child Protection and Safety Act H.R. 4472, $109^{\text {th }}$ Cong. (2006).

Canada Criminal Code, R.S.C. 1985, c. C-46 (§§150-182).

Criminal Code Act, 1995 Ch. 10, Sub. B and Chapter 11, Sub. D. (Austl.) 
Sexual Offences Act (2003) (UK).

Strafgesetzbuch [STGB] [Penal Code], Nov. 13, 1998, Bundesgesetzblatt [BGBI], ch. 13 (Ger.).

U.S. CONST. art. I, $\S 8$. 
